[16] A. Rochatx et A. Tapernoux. - Le Lait et ses dérivés. - Vigot Frères, éditeurs, 1942.

[17] A. Tapernoux et J.-J. Nicolas. - Les variations du taux des chlorures dans le lait au cours de l'évolution d'une mammite streptococcique. - Rev. Vét. et Journ. Méd. Vét. et Zoot., 1935, 8\%, p. 624 .

[18] G. Thieulin et R. Vuillaume. - Eléments pratiques d'analyse et d'inspection du lait. - Le Lait, édit., 1942 et 1948.

[19] Winter. - Constance du point de congélation de quelques liquides de l'organisme. Application à l'analyse du lait. - C. R. Acad. Sci., nov. 1895 , pp. 696-698.

\title{
ASPECTS NOUVEAUX DE LA MULTIPLICATION ET DU TRAITEMENT DES FERMENTS LACTIQUES
}

par

\author{
D. E. EAKLE, G. A. SANDERS et R. L. SELLARS
}

Les changements survenus en industrie laitière depuis 30 ans sont nombreux, variés. Les nouveaux procédés ont créé des problèmes. La multiplication et l'usage des ferments lactiques n'ont pas échappé à la tourmente générale.

Il est impossible d'imputer à une cause générale les difficultés rencontrées dans ce domaine particulier.

Les recherches effectuées voilà 30 ou 50 ans, sont à la base de la technique mais ne correspondent plus à nos conditions de travail. Prenons comme exemple la détermination du développement d'une culture lactique établie par le comptage bactériologique et la production d'acide.

Ce graphique repose sur un travail sérieux. Cependant cette courbe ne représente plus la croissance et le développement d'une culture lactique dans les conditions actuelles. Ainsi dans le temps :

a) Nous avions des cultures lentes, adaptées à nos méthodes de transformation;

b) Nous utilisions du lait cru ;

c) Les contrôles de température manquaient de précision ;

d) Seule la réfrigération à l'eau de puits existait. Aujourd'hui :

(1) Les auteurs donnent ici les résultats d'expériences poursuivies à : Culture Research Center, Chr. Hansen's Laboratory, Inc., 9015 W. Maples Street, Milwaukee, Wisconsin 53214.

(2) Le Québec laitier et alimentaire, 1964, no 9 et 10. 
a) Nous avons des cultures hybrides, rapidement activées ;

b) Nous utilisons un lait spécialement sélectionné et fortifié pour le développement des cultures;

c) Nous contrôlons avec précision les températures;

d) Nous avons la réfrigération mécanique.

Cependant nos méthodes de culture n'ont pas évolué au rythme des changements. Examinons le graphique 1. La courbe de croissance peut se diviser techniquement en 4 phases :

1) A-B - Phase lente : caractérisée par un départ lent et l'accélération de la croissance.

2) B-C - Phase logarithmée : caractérisée par une croissance maxima et une activité cellulaire maxima.

3) C-D - Phase stationnaire : période de stabilité où, théoriquement, il existe un équilibre entre la vie et la mortalité des cellules.

4) D-E - Phase morte : où les cellules qui meurent dépassent les vivantes. L'activité est considérablement réduite à ce stage.

En pratique fromagère, par exemple, nous désirons arrêter ou retarder les cultures lorsque le développement est au sommet,

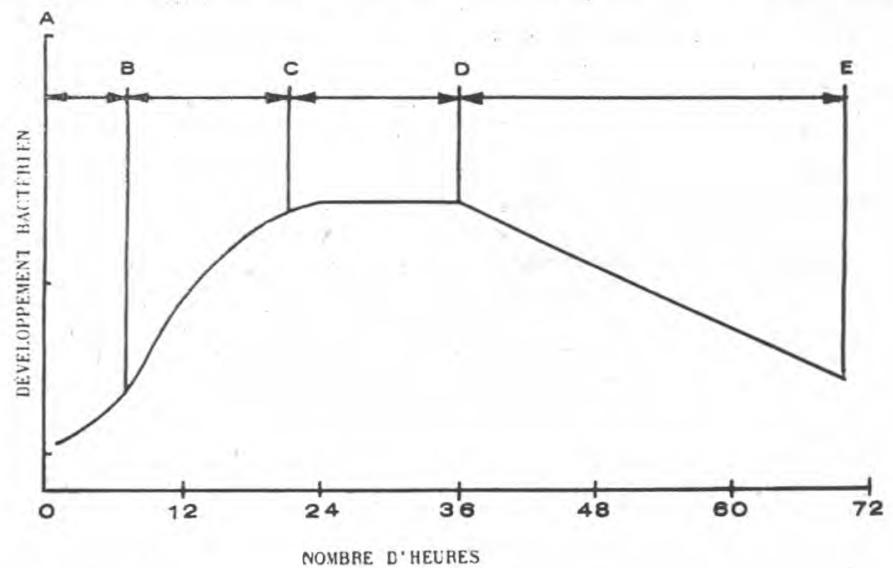

Graphique I. - Courbe théorique de croissance, montrant les phases du développement bactérien.

(juste avant C-D) ; pour obtenir une culture active nous la refroidissons à ce stage. C'est très bien en théorie. Mais nous jugeons ce point atteint, lorsque le lait est caillé. Dans le temps, c'était le seul indice que nous possédions et par tradition, nous avons continué de considérer la coagulation comme le critère d'une fermentation à point.

Cependant, un incident et l'esprit d'observation du personnel de nos laboratoires nous a fait tomber sur des faits qui renversent 
nos notions et peuvent s'établir comme une des plus importantes découvertes des derniers 50 ans en ce domaine : à savoir ce qu'il arrive aux cultures durant leur développement dans les conditions actuelles de fabrication et la découverte d'une méthode capable d'augmenter l'activité des cultures, sans qu'il en coûte un sou de plus.

Nos découvertes sont simples :

1) Les cultures lactiques dans les conditions actuelles ne se développent pas de la manière que nous avons toujours crue normale (graphique 1).

2) La croissance des cultures continue à une température beaucoup plus basse que celle que nous avons toujours acceptée comme réelle.

3) Les exigences alimentaires des cultures lactiques changent. totalement dans les conditions actuelles de propagation.

4) La production d'acide et l'aptitude à séparer le caillé du petit lait, peuvent être considérablement augmentées en multipliant les cultures à des températures réduites.

5) Le développement des phages - quoique nos expériences ne soient pas terminées - est considérablement réduit par des températures d'incubation réduites.

Avant de pousser plus loin la discussion, voici brièvement décrit le processus des expériences : les procédés d'expérimentation ont été tracés de façon à simuler et reproduire les méthodes de propagation généralement utilisées dans les fromageries.

1) La teneur du lait utilisé variait de 10 à 12 p. 100 de solides;

2) En tout temps le taux d'inoculation s'élevait à 1 p. 100 ;

3) L'ensemencement $d u$ ferment et la culture se faisaient dans du lait stérilisé complètement ou chauffé à la vapeur à $190^{\circ}-200^{\circ}$ durant 1 heure ;

4) La période d'incubation variait suivant l'expérience en cours;

5) L'analyse expérimentale de 43 couches commerciales soumises aux expériences a commencé après la $1^{\text {re }}$ heure pour se poursuivre jusqu'à la $144^{\mathrm{e}}$ heure. Cependant, la majorité des analyses ont été faites sur la période de 40 à 48 heures.

Les analyses et les méthodes utilisées furent en général les méthodes officielles ou standard.

1) L'énumération des bactéries vivantes fut faite selon la méthode modifiée standard de Ellifler, sur agar, en plaques incubées à 720 F.-5 jours. L'expérience nous a prouvé /que cette méthode donnait les meilleurs résultats.

2) Le développement de l'acide était déterminé par $p \mathrm{H}$ et acidité titrable et exprimé en p. 100 d'acide lactique. 
3) Les tests d'activité étaient basés sur le développement de l'acide d'une culture inoculée à 1 p. 100 dans un lait de 10 p. 100 de solides et incubé à $86^{\circ} \mathrm{F}$. durant 6 jours.

4) La quantité de lactose était déterminée par la méthode Perry et Doan (1950).

5) L'acide citrique a été déterminé selon la méthode Marier et Boulet (1958).

6) Les analyses Warburg ont été faites en suivant les directives consignées dans "Manometric Techniques" $4^{\mathrm{e}}$ Ed., par Umbriet et $\mathrm{Al}$.

Nous avons constaté, d'après les analyses effectuées selon le plan tracé, les faits suivants :

En fait, il est difficile de vérifier par simple regard, l'application pratique des données théoriques. Même si le développement d'une culture lactique suit théoriquement la courbe décrite dans le tableau 1 , tout changement dans le milieu environnant, ou dans les méthodes d'analyse vont changer les résultats et contredire les données passées. La courbe de croissance d'une culture bactériologique se conformera à la figure 1 , seulement si la culture est continuellement incubée à la même température. En pratique dans l'industrie, le ferment n'est pas propagé à une température constante sur une période de 24 à 48 heures. Au contraire, après une incubation normale de 14 à 16 heures ou après coagulation du ferment, selon la pratique habituelle, nous avons refroidi le ferment à $35-40^{\circ} \mathrm{F}$., aussi rapidement que possible.

Nous nous sommes alors posé plusieurs questions :

1) Qu'arrive-t-il alors au ferment?

2) Est-ce que quelqu'un a cherché à savoir quelle était la courbe de croissance d'une culture lactique dans ces conditions.

3) L'activité de la culture est-elle la même au cours du refroidissement que celle donnée par la production d'acide.

Accidentellement, un incubateur ne put maintenir la température désirée et tout ceci nous amena à vérifier différentes souches. Nous avons été alors à même de constater que presque toutes les souches commerciales s'éloignaient de la courbe classique de développement bactérien, dans le contexte industriel. Une seule sur 43 souches commerciales a démontré une croissance caractéristique. Ces cultures incubées à $70-72^{\circ} \mathrm{F}$. pendant 16 heures ont été refroidies à $35^{\circ} \mathrm{F}$. Après le refroidissement, le nombre des organismes vivants diminua pour une période de 2 à 12 heures. Cette diminution variait de 10 à 80 p. 100 du nombre initial d'organismes vivants. En continuant les épreuves et la durée du refroidissement, le pourcentage des organismes viables atteignait lentement mais régulièrement 90 à 95 p. 100 du nombre d'organismes vivants, antérieur au refroidissement. 


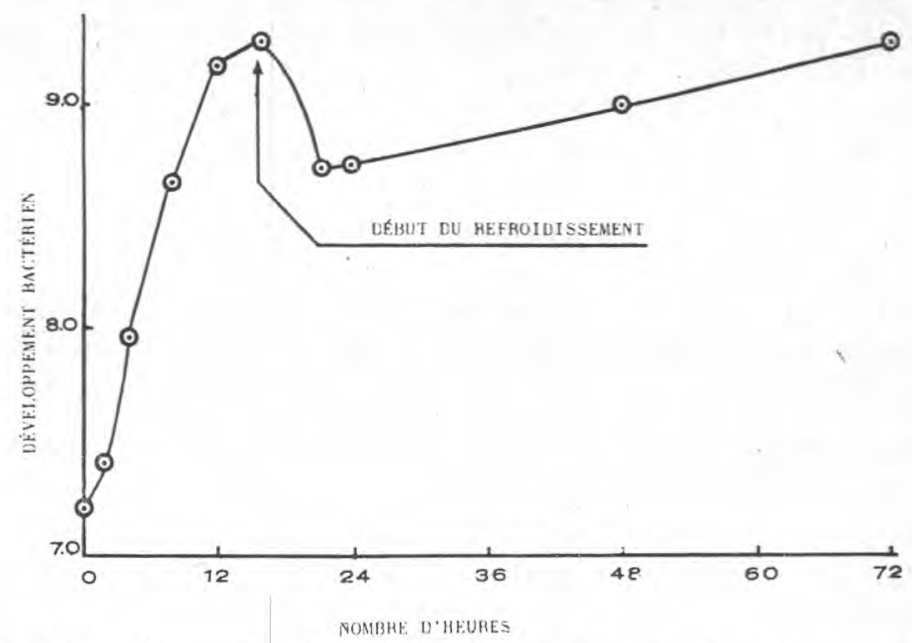

Graphique II. - Courbe de croissance moyenne dans des conditions normales d'une production commerciale: lait reconstitué à 12 p. 100 de solides non gras, chauffé à $190^{\circ} \mathrm{F}$, pendant une heure, refroidi à $72^{\circ} \mathrm{F}$. Inoculé avee 1 p. 100 de culture active, incubé 16 heures à 72 o $\mathrm{F}$, refroidi et maintenu à $35-40^{\circ} \mathrm{F}$.

Le temps requis pour que les eultures atteignent une viabilité égale au point de départ variait de 6 à 48 heures. Des essais répétés ont établi que le temps nécessaire à une telle revigorisation était une caractéristique particulière à chaque culture. Le graphique $\mathrm{n}^{\circ} \quad 2$ illustre une courbe caractéristique de croissance dans les conditions commerciales ordinaires.

Comme ces résultats indiquent une réduction significative du nombre de bactéries viables, jusqu'ici insoupçonnées, il fallait pousser les recherches pour obtenir réponse à deux questions :

1) Quelle est la température minimum d'incubation pour la préparation d'une culture apte à donner une activité suffisante, pour usage commercial ?

2) Est-ce que cette culture, au refroidissement, va être réduite en nombre d'organismes viables au point d'affecter son activité finale?

Un programme fut tracé qui permit de mesurer l'activité bactérienne par le comptage sur plaques des organismes vivants, par le $p \mathrm{H}$ et par le développement de l'acide à différentes températures et périodes d'incubation. Un essai de 8 différentes souches ont été soumises à des températures de $32^{\circ} \mathrm{F}$., $41^{\circ} \mathrm{F}$., $50^{\circ} \mathrm{F}$., $59^{\circ} \mathrm{F}$., $63^{\circ} \mathrm{F}$., $68^{\circ} \mathrm{F}$. et $72^{\circ} \mathrm{F}$. Les analyses ont été faites du début de l'incubation à intervalles réguliers 48 heures après incubation. Une première série de ces souches préparée avec une culture sèche et incubée immédiatement aux températures et durant le temps ci-dessus décrits. Une seconde série de cultures fut activée 
dans le lait et soumise à deux transferts, puis au $3^{\mathrm{e}}$ transfert inoubée aux températures et périodes de temps déterminées pour l'expérience.

Les résultats indiquent clairement que les souches de cultures diffèrent dans leur aptitude à déclencher et maintenir une croissance et développement idéal à basse température, selon que le point de départ est une culture sèche ou une culture activée. Dans cette partie de l'expérience, toutes les cultures préparées avec une culture sèche ont démontré un faible développement aux températures de $32^{\circ}$ et $41^{\circ} \mathrm{F}$. Cependant les mêmes souches, incubées après une période d'activation, montrèrent une croissance significative à $41^{\circ} \mathrm{F}$., quoique à $32^{\circ} \mathrm{F}$. les résultats étaient nuls. Quelle que soit la méthode initiale de propagation, l'incubation à plus de $50^{\circ} \mathrm{F}$. produisit un développement d'acide significatif.

Dans tous les cas, cependant, l'incubation à $50^{\circ} \mathrm{F}$. ou moins produit un développement trop lent pour avoir une valeur industrielle.

Pour des périodes d'incubation de 18 à 21 heures, à $59^{\circ}$ et $63^{\circ}$, le développement de l'acide et la croissance des organismes viables étaient très satisfaisants. Cependant une meilleure acidité et un meilleur développement bactérien se produisirent avec les cultures activées par 2 propagations à $72^{\circ} \mathrm{F}$. et incubées au $3^{\mathrm{e}}$ transfert à 59-630 F. que dans le cas des cultures sèches immédiatement propagées à $59-63^{\circ} \mathrm{F}$. Sept des huit souches ont donné de meilleurs résultats avec le $3^{\mathrm{e}}$ transfert incubé à $59-63^{\circ} \mathrm{F}$. que dans le cas de 3 transferts à $72^{\circ} \mathrm{F}$. Cependant, en quelques cas le nombre moyen de bactéries viables était inférieur dans les cultures incubées à $59^{\circ}-63^{\circ} \mathrm{F}$., qu'à plus haute température. Ceci posait de nouveaux points d'interrogation.

Comme un développement suffisant d'acide peut être obtenu au $3^{\mathrm{e}}$ transfert par une incubation du $3^{\mathrm{e}}$ transfert $59^{\circ}-63^{\circ} \mathrm{F}$., de nouveaux essais furent mis en marche pour déterminer l'effet du refroidissement sur la réduction des organismes viables. Le processus expérimental fut le suivant :

a) La culture témoin fut propagée normalement : incubation à $72^{\circ} \mathrm{F}$. pour 16 heures, refroidissement à l'eau glacée de $35^{\circ} \mathbf{F}$, ou moins et maintenu à cette température pour compléter 56 heures. du début de l'expérience.

b) Les cultures expérimentales subirent les mêmes traitements que la culture témoin, à l'exception qu'au $3^{\text {e }}$ transfert, l'incubation se fait entre $59^{\circ}$ et $63^{\circ} \mathrm{F}$. pendant 21 heures et 18 heures; le refroidissement, le temps de retenu, ete., sont la réplique du groupe $a$.

Les résultats (graphique 3 ) indiquent que les cultures incubées à une température inférieure, ne produisent pas un pourcentage significatif de réduction des organismes vivants, comme le fait la 
culture témoin. En quelques cas, cette réduction varie de 2 à 10 p. 100. Quoique le nombre d'organismes vivants sans les cultures incubées à $59^{\circ}$ et $63^{\circ}$ n'était pas aussi élevé que dans les cultures incubées à $72^{\circ} \mathrm{F}$., le pourcentage d'acide développé et le $p H$ étaient égaux à ceux de la culture de $72^{\circ} \mathrm{F}$. Ceci suppose une plus grande activité des organismes vivants. De nouveau, la culture témoin, après une diminution $d u$ nombre d'organismes vivants, reprit vigueur. Quelques cultures expérimentales ne révèlèrent aucune perte significative de vitalité et même démontrèrent un accroissement lent de vitalité durant l'incubation prolongée à $35^{\circ}-40^{\circ} \mathrm{F}$.

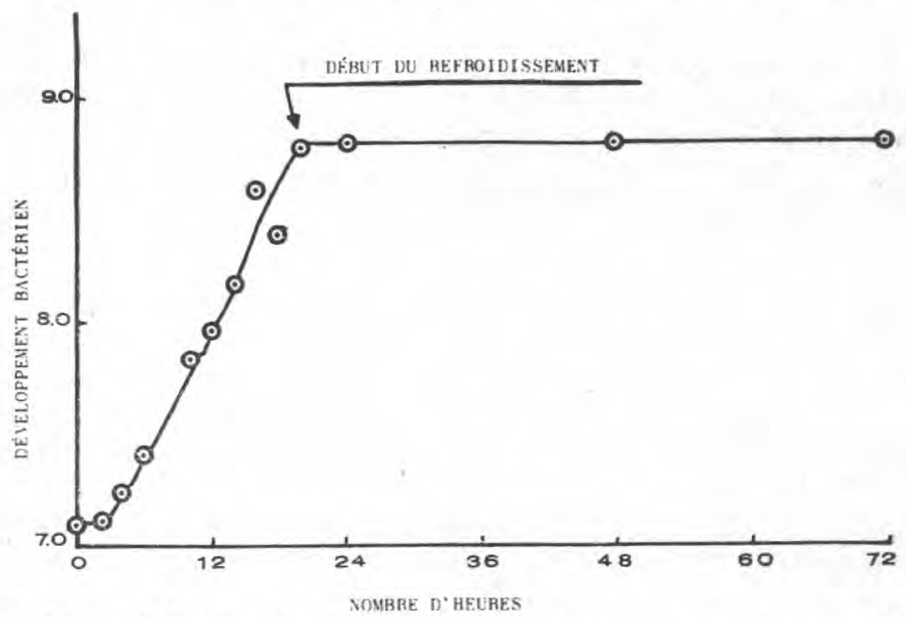

Graphique III. - Courbe de croissance moyenne obtenue dans les conditions expérimentales suivantes : lait reconstitué à 12 p. 100 de solides non gras, chauffé à $190^{\circ} \mathrm{F}$ pendant 1 heure, refroidi à $59^{\circ} \mathrm{F}$, inoculé avec 1 p. 100 de culture activée, incubé 21 heures à $50^{\circ} \mathrm{F}$., refroidi et maintenu à $35-40^{\circ} \mathrm{F}$.

Il apparaît done qu'un développement d'acide suffisant est possible au $3^{\mathrm{e}}$ transfert, lorsque l'incubation a lieu à $59^{\circ}{ }_{-63}^{\circ} \mathrm{F}$. pendant 21 et 18 heures, sans perte sensible de vitalité de la culture. Une nouvelle expérience fut donc tracée pour mesurer l'activité bactérienne durant toute la période d'incubation. Le pourcentage d'inoculation et le traitement à la chaleur du milieu de culture correspondaient en tout point aux expériences déjà décrites.

Le processus comportait :

a) Culture témoin : incubée à $72^{\circ} \mathrm{F}$. pendant 16 heures et refroidie à $35^{\circ} \mathrm{F}$.

b) Culture activée incubée à $72^{\circ} \mathrm{F}$. pendant 16 heures pour les deux premiers transferts, puis incubée à $59^{\circ} \mathrm{F}$. pendant 21 heures au troisième transfert et refroidie à $35^{\circ} \mathrm{F}$.

c) Même processus que dans B, à l'exception que la culture fut maintenue à $59^{\circ} \mathrm{F}$. durant toute l'expérience. 
Des analyses furent régulièrement faites sur ces ferments pour établir à différentes périodes :

1) Le nombre de bactéries vivantes;

2) Le $p \mathrm{H}$ et le pourcentage d'acide développé ;

3) La vitalité de la culture.

Remarquons qu'en ce cas particulier le $3^{\mathrm{e}}$ transfert est analogue au ferment commercial, selon les méthodes utilisées dans nombre de fromageries.

Les principaux facteurs établis durant cette expérience se résument à ceci : l'activité bactérienne est plus uniforme lorsque l'inoculation se fait à $59^{\circ} \mathrm{F}$., le refroidissement affecte moins l'activité bactérienne des cultures préparées à 59० $\mathrm{F}$. que de celles incubées à $72^{\circ} \mathrm{F}$. De plus la production d'acide se continue à un rythme lent avec les cultures incubées à $59^{\circ} \mathrm{F}$. mais sans perte d'activité. Les cultures incubées à $63^{\circ} \mathrm{F}$. ont donné des résultats comparables.

Le fait que le nombre des bactéries et le pourcentage d'acide augmentaient et que le $p H$ diminuait durant le refroidissement des cultures incubées à $59^{\circ} \mathrm{F}$., nous a amené à étudier les besoins alimentaires et l'aptitude à se développer, des cultures incubées à température modérée.

Les graphique IV et V donnent une idée de l'utilisation du lactose et du citrate, les deux éléments nutritifs de base des cultures lactiques commerciales.

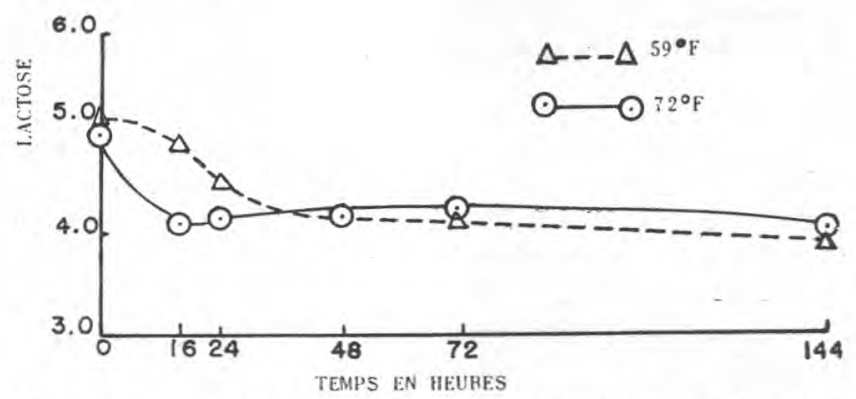

Graphique IV. - Courbe moyenne d'utilisation du lactose par des cultures commerciales mélangées, incubées à $72^{\circ} \mathrm{F}$, pendant 16 heures, puis refroidies à $35-40^{\circ} \mathrm{F}$, et incubées à $59{ }^{\circ} \mathrm{F}$ pendant 21 heures et refroidies à $35-40^{\circ} \mathrm{F}$.

Il est à remarquer que les cultures incubées à $72^{\circ} \mathrm{F}$. utilisent environ 19 p. 100 du lactose disponible et que les cultures de $59^{\circ} \mathrm{F}$. en utilisent environ 24 p. 100.

Cependant l'utilisation du citrate est beaucoup plus significative : $72^{\circ} \mathrm{F}$. utilise 67 p. 100 , tandis que $59^{\circ} \mathrm{F}$. utilise 97 p. 100.

Nous poursuivons actuellement des recherches pour comprendre mieux les caractéristiques biochimiques de ces cultures dans ces cas précis. 


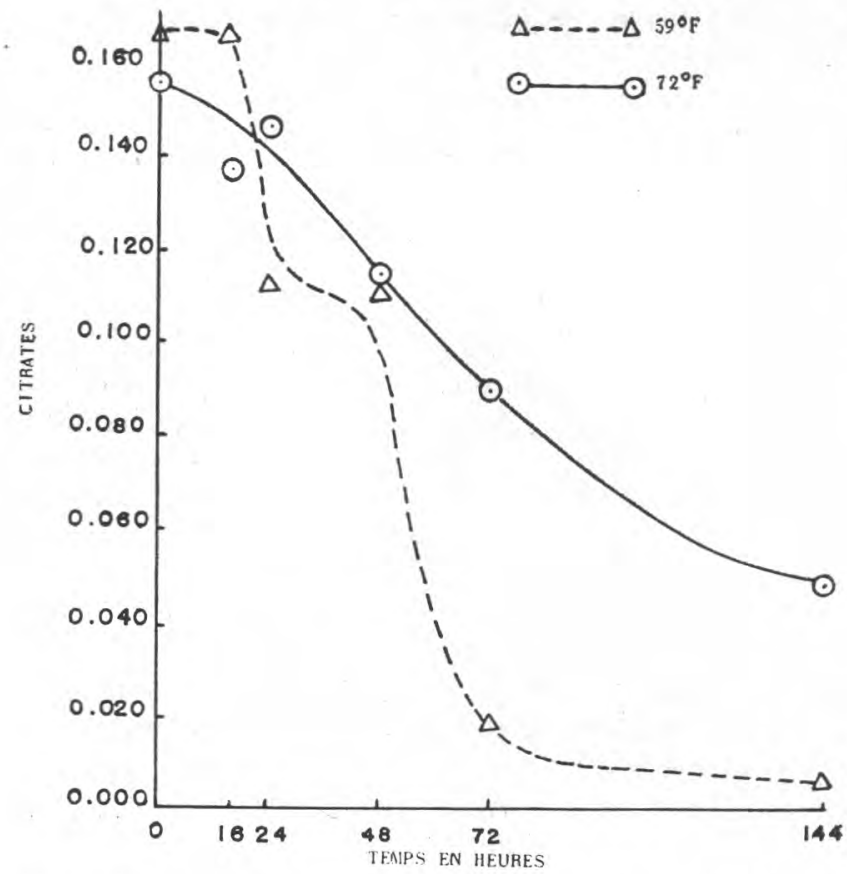

Graphique V. - Courbe moyenne de l'utilisation du citrate par des cultures commerciales mélangées, incubées à $72^{\circ} \mathrm{F}$ pendant 16 heures puis refroidies à $35-40^{\circ} \mathrm{F}$ : incubées à 59 o F pendant 21 heures et refroidies à $35-40^{\circ} \mathrm{F}$.

Les graphiques VI et VII donnent les résultats d'expérience ou l'absorption d'oxygène a été mesurée (au $3^{\mathrm{e}}$ transfert) lorsque ces cultures étaient incubées à $72^{\circ} \mathrm{F}$. et $59^{\circ} \mathrm{F}$. L'on remarquera que l'activité est considérablement moindre dans les cultures incubées à $72^{\circ} \mathrm{F}$. et refroidies de 2 à 24 heures, graphique IV que dans les cultures incubées à $59^{\circ} \mathrm{F}$. et refroidies pour les mêmes périodes, graphique VII.

L'on peut conclure que l'uniformité des cultures incubées à $59^{\circ} \mathrm{F}$. était meilleure et que l'activité augmentait après un refroidissement de 24 heures.

D'autres épreuves nous ont démontré que les ferments incubés entre $59^{\circ} \mathrm{F}$. et $63^{\circ} \mathrm{F}$. pour une période de temps assez longue avaient plus de vitalité que les ferments incubés à des températures plus élevées.

Ces données furent appliquées dans la fabrication du fromage Cheddar. Dans l'usine A, les conditions étaient idéales et aucun problème de classification n'existait. Dans l'usine $B$, les conditions sanitaires douteuses et des difficultés de classification étaient toujours présentes. 


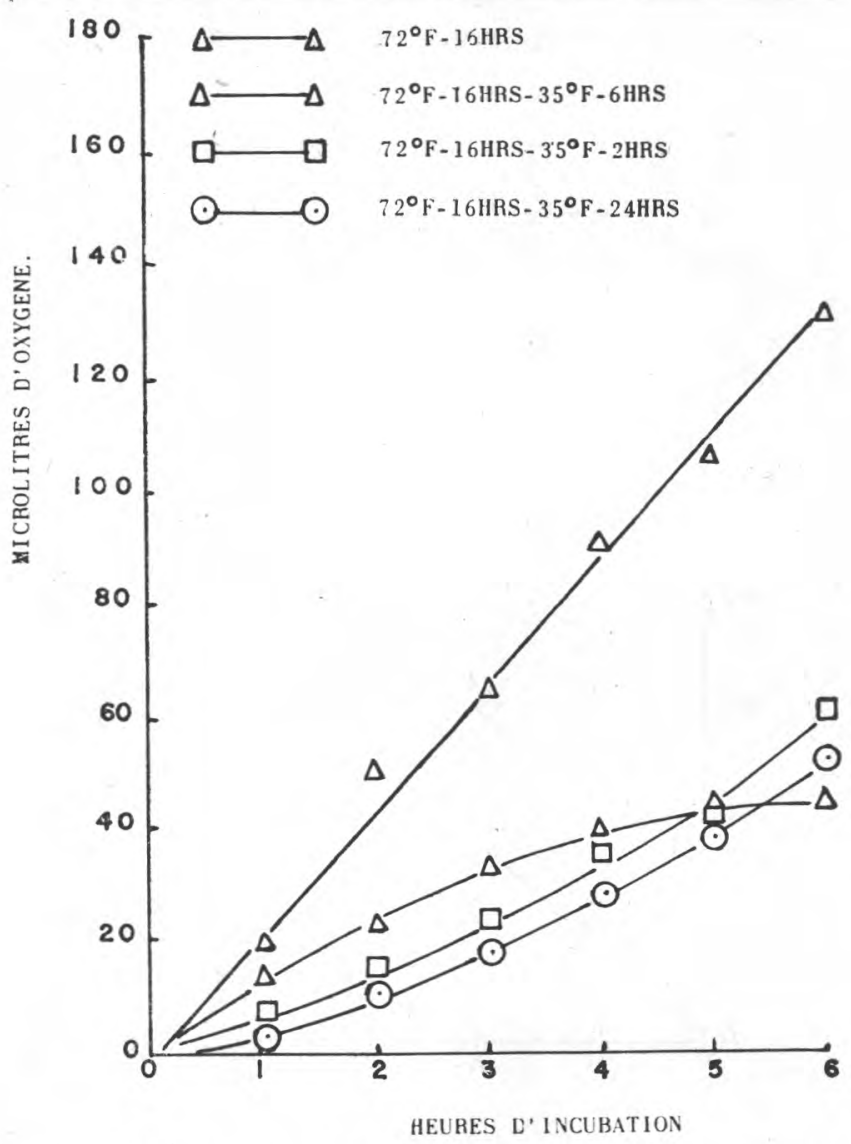

Graphique VI. - Consommation d'oxygène (activité) de cultures commerciales incubées durant 16 heures à $72{ }^{\circ} \mathrm{F}$ et analysées à différentes heures après le refroidissement.

Après une légère adaptation dans les procédés de fabrication, l'usine A produit un fromage de qualité qui après 9 mois avait une excellente saveur caractéristique et une bonne texture.

Dans l'usine B, des bassins conduits avec les ferments ordinaires, en parallèle avec des bassins usinés avec des ferments préparés à température moyénne, les résultats furent différents. Les ferments préparés à température moyenne, même dans des pauvres conditions hygiéniques donnèrent un bon fromage tandis que les fromages à procédés ordinaires développèrent des saveurs de fruits, etc.

Actuellement, de nombreuses usines aux Etat-Unis comme au Canada utilisent ce procédé de fabrication et leur succès est attribuable en bonne part à cette méthode de propagation des ferments. 


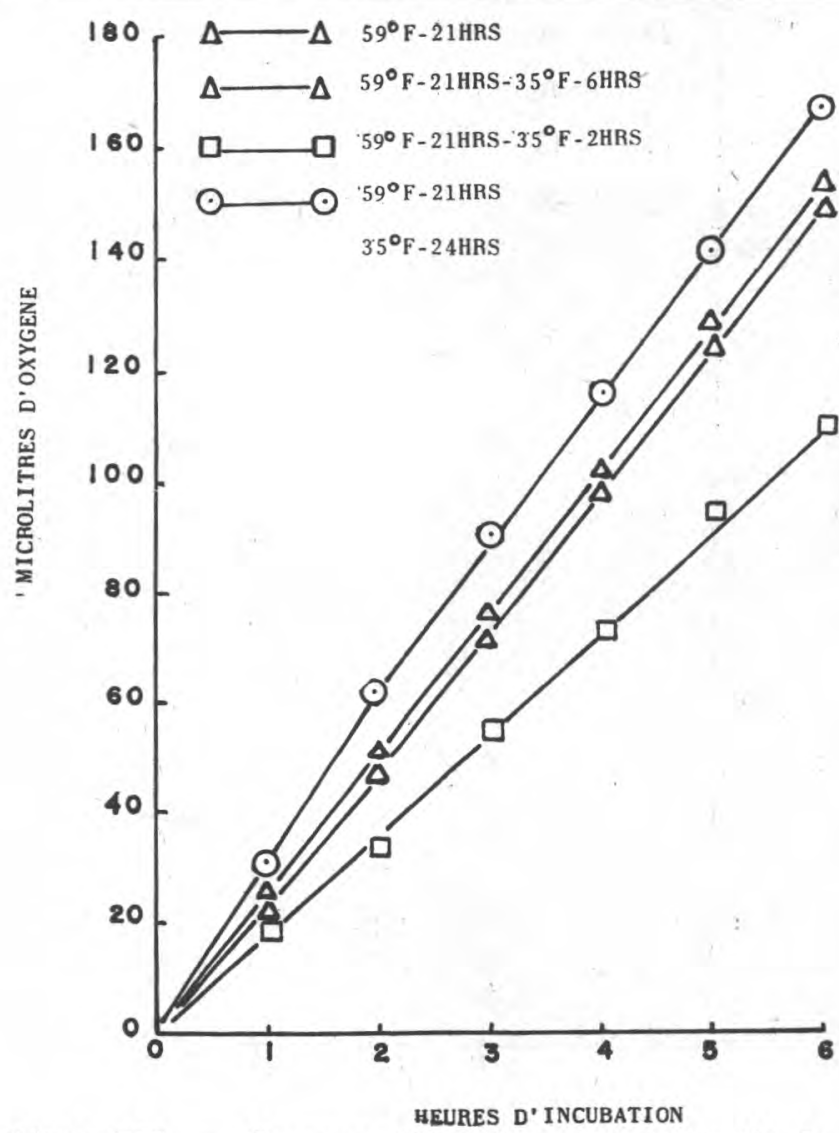

Graphique VII. - Consommation d'oxygène (activité) de cultures commerciales incubées 21 heures à $59^{\circ} \mathrm{F}$ et analysées à différentes heures après refroidissement.

D'autres recherches sont poursuivies, mais des résultats préliminaires indiquent que des cultures sensibles aux phages, soumises à des concentrations variées de bactériophages, sont moins susceptibles à la destruction si reproduites à des températures moyennes. Il a déjà été prouvé que les phages se reproduisent plus tranquillement à une température inférieure à $70^{\circ} \mathrm{F}$. Les phages ont diminué de 10 à 1000 fois en nombre à des basses températures. Cependant les résultats sont spécifiques à chaque type de phages. Le fait que la reproduction des phages est retardée par les basses températures d'incubation est significatif 'et mérite que l'on expérimente davantage la méthode de production des ferments à une basse température.

En raison de tous ces résultats, il semble que la propagation et la manipulation des ferments doivent être soumises aux modifications suivantes : 
1) La culture mère doit être traitée de la façon habituelle : c'est-à-dire ensemencement et transfert normal de la culture et incubation à $70^{\circ}-72^{\circ} \mathrm{F}$. pendant 14 à 16 heures.

2) La culture devrait être refroidie à $33^{\circ}-35^{\circ} \mathrm{F}$. et maintenue à cette température jusqu'à inoculation du ferment.

3) La propagation du ferment doit se faire de $59^{\circ}$ à $63^{\circ} \mathrm{F}$. pendant 21 à 18 heures respectivement avec une inoculation de 1 p. 100 pas moins.

4) Si les ferments sont refroidies, ils ne doivent pas l'être à une température inférieure à $50^{\circ} \mathrm{F}$. Ils peuvent être maintenus à $59^{\circ} \mathrm{F}$. pour 24 heures sans refroidissement, sans perte appréciable d'activité.

5) Il est recommandé que la culture mère ne doit pas être transférée plus de 3 fois avant de changer pour une culture fraîche.

Les résultats actuels indiquent que la culture mère perd de sa vitalité à sa $5^{\mathrm{e}}$ propagation. L'usage continu d'une même culture mère donnera des résultats inférieurs.

Sous l'impression que des pratiques identiques à cette méthode ont déjà été en honneur chez certains fromagers, nous avons procédé à une enquête dans les usines pour connaître leur méthode de propager les ferments. Dans les pays scandinaves, aux Etats-Unis et au Canada, certaines usines ont utilisé approximativement cette méthode.

Dans les pays scandinaves, la pratique veut que la multiplication des ferments se fasse à une température voisine de $63^{\circ} \mathrm{F}$. après une période d'incubation préliminaire de 2 heures à $68-72^{\circ} \mathrm{F}$. Coïncidence, c'est une des rares régions où les bactériophages n'ont pas causé d'ennui sérieux aux cultures lactiques. Cependant nos analyses nous ont démontré que ces cultures contenaient des phages en concentration de 100 à 10000 par ml. Ces concentrations sont capables dans les conditions ordinaires de causer des troubles.

Au Canada, plusieurs fromageries ont utilisé cette méthode de propagation à basse température qui même, y constituait la méthode courante, Aux Etats-Unis une seule fabrique semble avoir utilisé ce procédé et avec de bons résultats dans la fabrication de fromage Cheddar.

La raison principale pour usage de basses températures, fournie par les préposés au ferment était la suivante : "J'ai trouvé que cette méthode me donnait un ferment plus uniforme ». Cependant on semblait ignorer l'application du phénomène et en général on en était arrivé à cette pratique par pure chance. Le fait cependant que cette méthode produit des ferments d'excellente qualité, uniforme d'un jour à l'autre, d'une saveur supérieure, d'une bonne apparence et causant moins de troubles avec les phages. 
Nous avons essayé d'expliquer le pourquoi, le comment d'une méthode raisonnée. Comme derniers commentaires ajoutons :

Que l'usage prolongé d'une culture mère diminue l'efficacité du procédé provenant du mauvais équilibre des souches de cultures mixtes à mesure que l'on augmente les transferts.

Que cette méthode ne doit pas être considérée comme une panacée à tous les maux : elle ne saurait remplacer des méthodes de fabrication reconnues, un lait de bonne qualité ; et des pratiques sanitaires éprouvées. En tout temps, les procédés de fabrication des ferments et du fromage doivent correspondre aux normes de qualité établies et aux conditions sanitaires élémentaires.

\section{Summary}

The experiments which have been carried out have shown that the growth of lactic acid cultures occurs with temperatures much lower tham those which are generally accepted. Moreover, the alimentary requiements of these lactic acid cultures are different from those usually noticed. At last, the development of bactériophages is much less important with the aforesaid temperatures.

\section{BIBLIOGRAPHIE}

[1] J. R. Marier M. Boulet. "Direct Determination of Citrie Acid in Milk with an Improved Pyridine - Acetic Anhydride Method *. J. Dairy Sci., 41, p. 1683-1692 (1958).

[2] Perry N. A. and F. J. Doan. "A Picric Acid Method for the Simultaneous Determinations of Lactose and Sucrose in Dairy Products". J. Dairy Sci., 33, p. 176-185 (1950).

[3] E. A. Prill and B. W. Hammer. "A Colorimetric Method for the Determination of Diacetyl Iowa State College Journal of Science, 12, (3) p. 385-395, 1938.

[4] Standard Methods for the Examination of Dairy Products. Tenth Edition 1953, American Public Health Association, Inc.

[5] Umbriet, et Al. "Manometric Technique", Fourth Edition. Burgess Publishing Company, Minneapolis, Minn.

[6] Personnal Communications :

a) Mr. D. Rikli, Elver's Chesse Factory, Wisconsin ;

b) N. T. Tofte Jesperen, Chr. Hansen's Laboratory, Copenhagen, Den.;

c) Mr. Jack Barn, Ont. Dept. of Agr. Toronto, Ont., Canada ;

d) Mr. M. Regnier, Montreal Milk Prod. Coop. Montreal, Quebec, Canada ;

e) Prof. F. E. Nelsen, University of Arizona, Tucson, Ariz.

[7] W. E. SANDine, et Al. "A simple Apparatus for Measurement of Gas Production and Activity of Lactic Starter Cultures *. Milk Products Journal, 48, 12-13, 39-40 (1957). 